\title{
Association between Inflammatory and Obesity Markers in a Swiss Population- Based Sample (CoLaus Study)
}

\author{
Pedro Marques-Vidal ${ }^{a} \quad$ Murielle Bochud ${ }^{a} \quad$ François Bastardot $^{b} \quad$ Thomas Lüscher $^{c}$ \\ François Ferrero $^{d}$ Jean-Michel Gaspoz ${ }^{\mathrm{e}}$ Fred Paccaud $^{\mathrm{a}}$ Adrian Urwyler $^{f}$ \\ Roland von Känelg Christoph Hock ${ }^{\mathrm{h}} \quad$ Gérard Waeber $^{\mathrm{b}} \quad$ Martin Preisig $^{\mathrm{i}}$ \\ Peter Vollenweider ${ }^{b}$ \\ a Institute of Social and Preventive Medicine (IUMSP), Lausanne University Hospital, b Department of \\ Medicine, Internal Medicine, CHUV and Faculty of Biology and Medicine, Lausanne, 'Department of \\ Medicine, University of Zurich, Zurich, d Department of Psychiatry, University of Geneva, e Department \\ of Community Medicine, University of Geneva, Geneva, ${ }^{f}$ Cytolab, Dällikon, 9 Division of Psychosomatic \\ Medicine, Bern University Hospital Inselspital, and University of Bern, Bern, hDepartment of \\ Psychiatry, University Hospital Zurich, Zurich, 'Department of Psychiatry, CHUV, Lausanne, Switzerland
}

Key Words

IL-1 $\beta \cdot$ IL- $6 \cdot$ TNF- $\alpha \cdot$ hs-CRP $\cdot$ BMI $\cdot$ Waist circumference $\cdot$ Body composition $\cdot$ Population study

\begin{abstract}
Objective: To assess the associations between obesity markers (BMI, waist circumference and \%body fat) and inflammatory markers (interleukin-1 $\beta$ (IL-1 $\beta$ ); interleukin-6 (IL-6); tumor necrosis factor- $\alpha$ (TNF- $\alpha$ ) and high-sensitivity C-reactive protein (hs-CRP)). Methods: Population sample of 2,884 men and 3,201 women aged 35-75 years. Associations were assessed using ridge regression adjusting for age, leisure-time physical activity, and smoking. Results: No differences were found in IL-1 $\beta$ levels between participants with increased obesity markers and healthy counterparts; multivariate regression showed \%body fat to be negatively associated with IL-1 $\beta$. Participants with high \%body fat or abdominal obesity had higher IL-6 levels, but no independent association between IL- 6 levels and obesity markers was found on multivariate regression. Participants with abdominal obesity had higher TNF- $\alpha$ levels, and positive associations were found between TNF- $\alpha$ levels and waist circumference in men and between TNF- $\alpha$ levels and BMI in women. Obese participants had higher hs-CRP levels, and these differences persisted after multivariate adjustment; similarly, positive associations were found between hs-CRP levels and all obesity markers studied. Conclusion: Obesity markers are differentially associated with cytokine levels. \%Body fat is negatively associated with IL-1 $\beta$; BMI (in women) and waist circumference (in men) are associated with TNF- $\alpha$; all obesity markers are positively associated with hs-CRP.


Marques-Vidal et al.: Association between Inflammatory and Obesity Markers in a Swiss Population-Based Sample (CoLaus Study)

\section{Introduction}

Cytokines, such as interleukin $1 \beta$ (IL-1 $\beta$ ), interleukin 6 (IL-6), tumor necrosis factor (TNF- $\alpha$ ) and C-reactive protein (CRP) have important effects in inflammation and atherosclerosis. Elevated proinflammatory cytokine levels and high-sensitive CRP (hs-CRP) have been associated with an increased risk of developing coronary heart disease [1] or diabetes [2].

It has been suggested that obesity is a chronic inflammatory condition [3], with increased production of cytokines and hs-CRP by adipocytes [4]. Still, the effects of each obesity marker (BMI, waist circumference or \%body fat) on cytokine levels remain to be clarified. For instance, BMI does not differentiate between lean and fat mass [5], while waist circumference relates only to the abdominal accumulation of fat. Further, most studies which assessed the independent effects of each obesity marker on cytokine levels did so by multivariate linear regression [6,7], a method that might lead to inflated estimates when multicollinearity (i.e. correlation) of the independent variables (i.e. obesity markers) exists. Multicollinearity can distort the interpretation of a model by increased inaccuracy of the regression coefficients and their standard errors [8]. Regression coefficients biased by collinearity might cause variables that have no significant relationship with the outcome (i.e. cytokine levels) when considered in isolation to become highly significant in conjunction with collinear variables, thus increasing type I error (false-positive results). Multiple regression coefficients might also show no statistical significance due to large confidence intervals, thus increasing type II error (false-negative results).

Hence, we used the data from the large, population-based CoLaus study to assess the association of different obesity markers with cytokine levels by ridge regression, a method whose goal is to circumvent the problem of collinearity between independent variables [9]. To our knowledge, this is currently the largest population study that has cytokine levels measured.

\section{Participants and Methods}

\section{Recruitment}

The CoLaus Study was approved by the Institutional Ethics Committee of the University of Lausanne. The CoLaus Study is a cross-sectional study aimed at assessing the prevalence and identifying the molecular determinants of cardiovascular risk factors in the Caucasian population of Lausanne, Switzerland, a town of 117,161 inhabitants, of which 79,420 are of Swiss nationality. The sampling procedure of the CoLaus Study has been described previously [10]. Briefly, the complete list of Lausanne inhabitants aged $35-75$ years $(n=56,694)$ was provided by the population registry of the city. A simple, nonstratified random sample of $35 \%$ of the overall population was drawn. The following inclusion criteria were applied: i) written informed consent; ii) age 35-75 years; iii) willingness to take part in the examination and to donate blood samples; iv) Caucasian origin, defined as having both parents and grandparents born in a restricted list of countries (available from the authors). Recruitment began in June 2003 and ended in May 2006. Participation rate was $41 \%$.

All participants attended the outpatient clinic of the University Hospital of Lausanne in the morning after an overnight fast. Data were collected by trained field interviewers in a single visit lasting about 60 $\min$.

Lifestyle and Clinical Data

According to their smoking histories, participants were classified as never, current, or former smokers. Leisure-time physical activity was considered if the participant took part for at least 20 min in leisure physical activities (tennis, running, football) two or more times per week. 
Anthropometric Measurements and Bioimpedance

Body weight and height were measured with participants standing without shoes in light indoor clothes. Body weight was measured in kilograms to the nearest $100 \mathrm{~g}$ using a Seca ${ }^{\circledR}$ scale, which was calibrated regularly. Height was measured to the nearest $5 \mathrm{~mm}$ using a Seca ${ }^{\circledR}$ height gauge. Overweight was defined as a BMI $\geq 25$ and $<30 \mathrm{~kg} / \mathrm{m}^{2}$; obesity was defined as a BMI $\geq 30 \mathrm{~kg} / \mathrm{m}^{2}$.

Waist circumference was measured with a non-stretchable tape over the unclothed abdomen at the narrowest point between the lowest rib and the iliac crest. Two measures were made and the mean (expressed in centimeters) was used for analyses. Abdominal obesity was considered for a waist circumference $>102 \mathrm{~cm}$ for men and $>88 \mathrm{~cm}$ for women [11].

Body composition was assessed by electrical bioelectrical impedance analysis (BIA) using the Bodystat ${ }^{\circledR} 1500$ analyzer (Isle of Man, British Isles, UK). This device has been validated against reference methods [12]. The coefficient of variation for repeated measurements of electrical impedance is $0.7 \%$ [12]; the reproducibility has been shown to be between 1\% [12] and 5\% [13]; the intraclass correlation coefficient has been estimated at 0.99 [14], and its correlation with reference methods such as isotope dilution is between 0.86 [13] and 0.96 [15]. All metallic adornments were removed, and measurement was performed after a 10-min rest in the supine position. Care was taken that the subject did not touch any metallic component of the bed and that the inner part of the thighs did not touch each other. The electrodes were positioned in the right side of the body according to the manufacturer's recommendations: injecting leads were connected to the electrodes behind the finger and toe, whereas measuring leads were connected to the electrodes on the wrist and ankle. Measurement was conducted with a test current of $400 \mu \mathrm{A}$ (root mean square) at a frequency of $50 \mathrm{kHz}$, with an impedance measuring range of 30-1,000 $\Omega$ (accuracy $3 \Omega$ ). Conversely, no information was available regarding the equation used (proprietary). Body fat was expressed as percentage of total body weight (\%body fat), and participants in the highest sex-specific quartile ( $>28 \%$ in men and $>40 \%$ in women) were considered as presenting with high body fat.

Cytokine Measurement

Venous blood samples $(50 \mathrm{ml})$ were drawn in the fasting state. hs-CRP was assessed by immunoassay and latex HS (IMMULITE 1000-High, Diagnostic Products Corporation, Los Angeles, CA, USA) with maximum intra- and interbatch coefficients of variation of $1.3 \%$ and $4.6 \%$, respectively. Serum was preferred to plasma as it has been shown that different anticoagulants may affect absolute cytokine levels differently [16]. It has also been stated that cytokine levels in a single blood sample may be useful biomarkers of inflammation in population-based studies of obesity-related diseases [16]. Serum samples were kept at $-80^{\circ} \mathrm{C}$ before assessment of the other cytokines and sent on dry ice to the laboratory. Cytokine levels were measured using a multiplexed particle-based flow cytometric cytokine assay, a methodology used in other studies [17]. Milliplex kits were purchased from Millipore (Zug, Switzerland). The procedures closely followed the manufacturer's instructions. The analysis was conducted using a conventional flow cytometer (FC500 MPL, BeckmanCoulter, Nyon, Switzerland). Lower detection limits for IL-1 $\beta$, IL-6, and TNF- $\alpha$ were $0.2 \mathrm{pg} / \mathrm{ml}$ in each case. Data regarding agreement between signal and cytokine levels, intra- and interassay coefficients of variation and correlation between repeated measurements have been reported elsewhere [18].

\section{Statistical Analysis}

Statistical analysis was conducted using SAS v.9.2 (SAS Inc, Cary, NC, USA), stratifying by gender. Quantitative variables (apart from inflammatory biomarkers) were expressed as mean \pm standard deviation and qualitative variables as number of participants and percentage. Inflammatory biomarkers were presented as percentage of values below detection limit, median and interquartile range of measured values, and as exponentiated multivariate-adjusted mean \pm standard error. Undetectable values were included in the first quartile. Between groups comparisons were performed using Student's t-test or Kruskall-Wallis nonparametric test for quantitative and chi-square test for qualitative variables. The bivariate association between cytokines and obesity markers was assessed by Spearman nonparametric correlation.

The association between the different obesity markers (BMI, waist circumference, and \%body fat) and inflammatory biomarkers was assessed by multivariate analysis including all obesity markers in the same model. As age, leisure-time physical activity, and smoking have been associated with cytokine levels, they were included in all multivariate models. The association of each obesity marker taken separately 
was assessed by multivariate linear regression on log-transformed values of detectable IL-1 $\beta$, Il-6, TNF- $\alpha$, and hs-CRP. As BMI, waist circumference, and \%body fat are closely associated, their independent associations with inflammatory markers were assessed in a second multivariate a nalysis using ridge regression applied on all obesity markers. Ridge regression is a variant of ordinary multiple linear regression whose goal is to circumvent the problem of predictors' collinearity [9]. When the predictor variables are highly correlated amongst themselves, the coefficients of the resulting least squares fit may be very imprecise. By allowing a small amount of bias in the estimates, more reasonable coefficients may often be obtained. Briefly, ridge regression implies that a constant number $\delta$ (penalty) is added to the elements on the diagonal of the matrix to be inverted. Let X be an $n \times(p+1)$ matrix of the $p$ independent variables obtained in $\mathrm{n}$ subjects; let $\mathrm{X}^{\mathrm{T}}$ be the transposed matrix of $\mathrm{X}$; let $\mathrm{Y}$ be an $\mathrm{n} \times 1$ vector corresponding to the dependent variable (i.e. IL-1 $\beta$ levels). The usual linear regression estimates ( $\beta$ values) are obtained via the matrix product $\left(\mathrm{X}^{\mathrm{T}} \times \mathrm{X}\right)^{-1} \times \mathrm{X}^{\mathrm{T}} \times \mathrm{Y}$. The ridge regression estimates are obtained via the matrix product $\left(\mathrm{X}^{\mathrm{T}} \times\right.$ $\mathrm{X}+\delta \mathrm{I})^{-1} \times \mathrm{X}^{\mathrm{T}} \times \mathrm{Y}$, where $\mathrm{I}$ is the $\mathrm{p} \times \mathrm{p}$ identity matrix, $\mathrm{X}$ is an $\mathrm{n} \times \mathrm{p}$ matrix of the centered independent variables, and $\delta$ is the penalty. It has been shown that ridge regression estimators have smaller mean square error than the ordinary least-squares estimators, provided $\delta$ is small enough [19]. Prior to analysis, the effect on the variance inflation factor (VIF) of ridge parameter values from 0 to 0.24 was assessed for each gender and the value of 0.18 (corresponding to a VIF close to unity) was chosen. Statistical significance was considered for $\mathrm{p}<0.05$.

\section{Results}

\section{Clinical Characteristics of Participants}

Of the 6,188 initial participants, 103 (1.7\%) were excluded because of missing cytokine data, and a further $55(0.9 \%)$ because of missing data for at least one of the anthropometric markers. The clinical characteristics of the remaining 6,030 (2,863 men and 3,167 women) are summarized in table 1. Men were significantly younger, had a higher BMI, and smoked more than women. Conversely, no gender differences were found for leisure-time physical activity.

Among the 6,030 participants, 2,289 (37.6\%), 451 (7.4\%) and 43 (0.7\%) had IL-1 $\beta$, IL-6 and TNF- $\alpha$ levels below detection limits, respectively. The distribution of IL-1 $\beta$, IL- 6 , TNF- $\alpha$, and hs-CRP levels stratified by gender according to the different obesity markers studied are summarized in tables 2 and 3.

\section{Associations between Obesity Markers and Cytokine Levels}

Men with high BMI had lower IL-1 $\beta$ levels, but this association was no longer significant after multivariate analysis (table 2 ). In women, high \%body fat and abdominal obesity were associated with lower IL-1 $\beta$ levels, but this association was no longer significant after multivariate adjustment (table 2). \%Body fat and waist circumference (men only) were significantly and negatively correlated with IL-1 $\beta$ levels, while no association was found for BMI (table 4). On multivariate ridge regression, \%body fat was independently and significantly associated with IL-1 $\beta$ levels in women, with a borderline significant association $(p=0.053)$ in men (table 4).

In both genders, IL-6 levels increased with greater levels of BMI, waist circumference, and \%body fat. After multivariate adjustment, these associations remained significant in women while in men only the association with abdominal obesity remained significant (table 2). In both genders, all obesity markers were individually and positively correlated with IL-6 levels (table 4), but this association was no longer significant after multivariate ridge regression (table 4).

In both genders, TNF- $\alpha$ levels increased with greater levels of BMI, waist circumference, and \%body fat (table 3); after multivariate adjustment these associations remained significant in women while in men only the association with abdominal obesity remained signif- 
Table 1. Clinical characteristics of the sample, by gender ${ }^{a}$

\begin{tabular}{|c|c|c|c|}
\hline & Men $(\mathrm{N}=2,863)$ & Women $(\mathrm{N}=3,167)$ & Test \\
\hline Age, years & $52.6 \pm 10.8$ & $53.5 \pm 10.7$ & $3.52^{* * *}$ \\
\hline \multicolumn{4}{|l|}{ Smoking status (\%) } \\
\hline Never & $921(32.2)$ & $1,496(47.2)$ & \\
\hline Former & $1,106(38.6)$ & $887(28.0)$ & $147.6^{* * *}$ \\
\hline Current & $836(29.2)$ & $784(24.8)$ & \\
\hline Leisure-time physical activity (\%) & $1,838(64.2)$ & $2,058(65)$ & $0.40^{\mathrm{NS}}$ \\
\hline $\mathrm{BMI}, \mathrm{kg} / \mathrm{m}^{2}$ & $26.6 \pm 4.0$ & $25.1 \pm 4.8$ & $12.77^{* * *}$ \\
\hline \multicolumn{4}{|l|}{ BMI categories (\%) } \\
\hline Normal & $1,078(37.7)$ & $1,812(57.2)$ & \\
\hline Overweight & $1,306(45.6)$ & $902(28.5)$ & $246.4^{* * *}$ \\
\hline Obese & $479(16.7)$ & $453(14.3)$ & \\
\hline Waist circumference, $\mathrm{cm}$ & $96 \pm 11$ & $83 \pm 12$ & $40.30^{* * *}$ \\
\hline Abdominal obesity (\%) & $681(23.8)$ & $974(30.8)$ & $36.67^{* * *}$ \\
\hline$\%$ Body fat & $23.8 \pm 6.1$ & $34.3 \pm 8.2$ & $56.20^{* * *}$ \\
\hline Dosable IL-1 $\beta(\%)$ & $132(60.5)$ & $225(63.9)$ & $7.60^{* *}$ \\
\hline IL-1 $\beta, \mathrm{pg} / \mathrm{ml}$ & $1.10(0.45-3.97)$ & $1.28(0.52-3.76)$ & $3.65^{\mathrm{NS}}$ \\
\hline Dosable IL-6 (\%) & $278(93.5)$ & $206(91.8)$ & $6.95^{* *}$ \\
\hline IL-6, pg/ml & $1.58(0.77-3.85)$ & $1.37(0.67-3.23)$ & $19.68^{* * *}$ \\
\hline Dosable TNF- $\alpha(\%)$ & $244(99.3)$ & $343(99.2)$ & $0.19^{\mathrm{NS}}$ \\
\hline $\mathrm{TNF}-\alpha, \mathrm{pg} / \mathrm{ml}$ & $3.06(1.90-4.66)$ & $2.75(1.73-4.42)$ & $23.65^{* * *}$ \\
\hline hs-CRP, mg/dl & $1.2(0.6-2.5)$ & $1.3(0.6-2.9)$ & $6.74^{* *}$ \\
\hline
\end{tabular}

${ }^{a}$ Results are expressed as mean \pm standard deviation (except cytokines), median and (interquartile range) of dosable values (cytokines) or as number of subjects and (percentage). Statistical analysis by Student's t-test or Kruskall-Wallis nonparametric test for quantitative variables and by chi-square for qualitative variables: ${ }^{N S}$ not significant; ${ }^{*} \mathrm{p}<0.05 ;{ }^{* *} \mathrm{p}<0.01 ;{ }^{* * *} \mathrm{p}<0.001$.

icant (table 3). Taken individually, all obesity markers were significantly and positively correlated with TNF- $\alpha$. Conversely, after multivariate ridge regression only BMI (in women) and waist circumference (in men) were significantly and positively associated with TNF- $\alpha$ (table 4).

In both genders, hs-CRP levels increased with greater levels of BMI, waist circumference, and \%body fat, and these associations remained significant after multivariate adjustment (table 3). All obesity markers were significantly and positively associated with hs-CRP, both on bivariate correlation or on multivariate ridge regression (table 4).

\section{Discussion}

To our knowledge, this is currently the largest population-based sample in which the associations between different obesity markers and IL-1 $\beta$, IL-6, TNF- $\alpha$, and hs-CRP have been assessed. Further, most studies [6, 7] assessed the independent associations of each obesity marker with cytokine levels by multivariate linear regression, which is prone to error when the independent variables are correlated In this study, the results of the linear regression were confirmed by a method which corrects for such a correlation and by using log-transformed values to reduce skewness.

IL-1 $\beta$ comes from the interleukin 1 family, which comprises 11 different proteins encoded by 11 distinct genes. In mice, IL-1 induces anorexia [20], although no differences in 
Marques-Vidal et al.: Association between Inflammatory and Obesity Markers in a Swiss Population-Based Sample (CoLaus Study)

Table 2. IL-1 $\beta$ and IL- 6 distribution according to different markers of obesity, by gender ${ }^{1}$

\begin{tabular}{|c|c|c|c|c|c|c|}
\hline & \multicolumn{3}{|l|}{ IL-1 $\beta$} & \multicolumn{3}{|l|}{ IL-6 } \\
\hline & $\begin{array}{l}\text { values > } \\
\text { LOD }(\mathrm{N})^{\mathrm{a}}\end{array}$ & median (IQR) ${ }^{\mathrm{b}}$ & $\begin{array}{l}\text { multi- } \\
\text { adjusted }^{c}\end{array}$ & $\begin{array}{l}\text { values > } \\
\text { LOD }(\mathrm{N})_{a}\end{array}$ & median (IQR) ${ }^{\mathrm{b}}$ & $\begin{array}{l}\text { multi- } \\
\text { adjusted }^{c}\end{array}$ \\
\hline \multicolumn{7}{|l|}{$\operatorname{Men}(N=2,863)$} \\
\hline \multicolumn{7}{|l|}{ BMI categories $\S$} \\
\hline Normal (n = 1,078) & $670(62.2)$ & $1.24(0.49-4.50)$ & $1.59 \pm 1.06$ & 989 (91.7) & $1.52(0.71-3.87)$ & $1.97 \pm 1.04$ \\
\hline Overweight $(\mathrm{n}=1,306)$ & 779 (59.7) & $1.00(0.45-3.93)$ & $1.44 \pm 1.06$ & 1,225 (93.8) & $1.50(0.75-3.67)$ & $1.88 \pm 1.04$ \\
\hline Obese $(n=479)$ & $283(59.1)$ & $0.94(0.40-2.89)$ & $1.30 \pm 1.10$ & $464(96.9)$ & $1.87(0.93-4.11)$ & $2.15 \pm 1.06$ \\
\hline Test & $2.03^{\mathrm{NS}}$ & $6.21^{*}$ & $1.74^{\mathrm{NS}}$ & $14.68^{* * *}$ & $7.46^{*}$ & $1.72^{\mathrm{NS}}$ \\
\hline \multicolumn{7}{|l|}{ High \%body fat t $^{\S \S}$} \\
\hline No $(n=2,157)$ & $1,340(62.1)$ & $1.15(0.46-4.13)$ & $1.50 \pm 1.04$ & $2,004(92.9)$ & $1.48(0.71-3.68)$ & $1.90 \pm 1.03$ \\
\hline Yes $(n=706)$ & $392(55.5)$ & $0.90(0.43-3.11)$ & $1.38 \pm 1.08$ & $674(95.5)$ & $1.90(0.98-4.21)$ & $2.15 \pm 1.06$ \\
\hline Test & $9.69^{* *}$ & $3.61^{\mathrm{NS}}$ & $0.74^{\mathrm{NS}}$ & $5.77^{*}$ & $17.34^{* * *}$ & $3.92^{*}$ \\
\hline \multicolumn{7}{|l|}{ Abdominal obesity $§ \S \S$} \\
\hline No $(n=2,182)$ & $1,345(61.6)$ & $1.11(0.46-4.09)$ & $1.47 \pm 1.04$ & $2,020(92.6)$ & $1.49(0.71-3.70)$ & $1.89 \pm 1.03$ \\
\hline Yes $(n=681)$ & 387 (56.8) & $1.00(0.43-3.34)$ & $1.46 \pm 1.08$ & $658(96.6)$ & $1.90(0.94-4.27)$ & $2.19 \pm 1.05$ \\
\hline Test & $5.03^{*}$ & $0.75^{\mathrm{NS}}$ & $0.01^{\mathrm{NS}}$ & $14.06^{* * *}$ & $15.92^{* * *}$ & $6.10^{*}$ \\
\hline \multicolumn{7}{|l|}{ Women $(N=3,167)$} \\
\hline \multicolumn{7}{|l|}{ BMI categories $\S$} \\
\hline Normal $(\mathrm{n}=1,812)$ & $1,179(65.1)$ & $1.36(0.55-4.02)$ & $1.57 \pm 1.05$ & $1,629(89.9)$ & $1.23(0.60-3.23)$ & $1.66 \pm 1.04$ \\
\hline Overweight $(n=902)$ & $569(63.1)$ & $1.20(0.47-3.74)$ & $1.54 \pm 1.06$ & $840(93.1)$ & $1.30(0.69-2.80)$ & $1.65 \pm 1.05$ \\
\hline Obese $(n=453)$ & 277 (61.2) & 1.07 (0.49-2.93) & $1.5 \pm 1.09$ & $437(96.5)$ & $2.03(1.03-3.91)$ & $2.34 \pm 1.07$ \\
\hline Test & $2.82^{\mathrm{NS}}$ & $2.88^{\mathrm{NS}}$ & $0.11^{\mathrm{NS}}$ & $23.79 * * *$ & $43.37^{* * *}$ & $11.55^{* * *}$ \\
\hline \multicolumn{7}{|l|}{ High \%body fat ${ }^{\S \S}$} \\
\hline No $(n=2,320)$ & $1,512(65.2)$ & $1.35(0.53-4.09)$ & $1.59 \pm 1.04$ & $2,093(90.2)$ & $1.25(0.61-3.22)$ & $1.68 \pm 1.03$ \\
\hline Yes $(n=847)$ & $513(60.6)$ & $1.10(0.47-3.17)$ & $1.44 \pm 1.07$ & $813(96.0)$ & $1.60(0.88-3.25)$ & $1.93 \pm 1.05$ \\
\hline Test & $5.71^{*}$ & $6.06^{*}$ & $1.59^{\mathrm{NS}}$ & $27.32^{* * *}$ & $18.55^{* * *}$ & $5.10^{*}$ \\
\hline \multicolumn{7}{|l|}{ Abdominal obesity $§ \S \S$} \\
\hline No $(n=2,193)$ & $1,425(65.0)$ & $1.37(0.54-4.08)$ & $1.61 \pm 1.04$ & $1,978(90.2)$ & $1.22(0.60-3.04)$ & $1.63 \pm 1.03$ \\
\hline Yes $(n=974)$ & $600(61.6)$ & $1.00(0.47-3.21)$ & $1.43 \pm 1.06$ & 928 (95.3) & $1.70(0.87-3.54)$ & $2.03 \pm 1.05$ \\
\hline Test & $3.34^{\mathrm{NS}}$ & $6.63^{* *}$ & $2.64^{\mathrm{NS}}$ & $23.03^{* * *}$ & $34.99 * * *$ & $15.34^{* * *}$ \\
\hline
\end{tabular}

${ }^{1}$ Results are expressed as number of subjects (percentage) with values above the lower limit of detection (LOD), median and interquartile range (IQR) for values above LOD and exponentiated multivariate-adjusted average \pm standard error for values above LOD. Statistical analysis by ${ }^{\mathrm{a}}$ chi-square, ${ }^{\mathrm{b}}$ Kruskall-Wallis test and ${ }^{\mathrm{c}}$ general linear model on log-transformed values adjusting for age (continuous), smoking ( 3 groups), and leisure-time physical activity ( 2 groups): ${ }^{{ }^{N S}}$ not significant; ${ }^{*} \mathrm{p}<0.05 ;{ }^{* *} \mathrm{p}<0.01 ;{ }^{* * *} \mathrm{p}<0.001$.

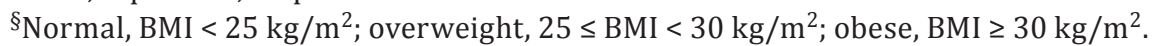

$\S$ Defined as a \%body fat $\geq 28 \%$ in men and $\geq 40 \%$ in women.

$\S \S$ Defined as a waist $>102 \mathrm{~cm}$ in men and $>88 \mathrm{~cm}$ in women.

IL-1 $\beta$ levels between patients with anorexia nervosa and normal-weight subjects have been found [21]. In this study, negative associations between IL-1 $\beta$ levels and obesity markers were found, with \%body fat being the only obesity marker associated with IL-1 $\beta$ levels on multivariate analysis in women with a similar borderline significant $(p=0.053)$ trend in men. The lack of significance among men might be related to a lower statistical power due to a small sample size; indeed, the multivariate-adjusted estimate of the slope in men was comparable to that in women (table 4). These findings are in agreement with the previously reported effect of IL-1 in mice, i.e., lower adipocyte numbers and reduced dietary intake, 
Table 3. TNF- $\alpha$ and CRP distribution according to different markers of obesity, by gender ${ }^{1}$

\begin{tabular}{|c|c|c|c|c|c|c|}
\hline & \multicolumn{3}{|l|}{ TNF- $\alpha$} & \multicolumn{3}{|l|}{ CRP } \\
\hline & $\begin{array}{l}\text { values > } \\
\text { LOD }(\mathrm{N})^{\mathrm{a}}\end{array}$ & median (IQR) ${ }^{\mathrm{b}}$ & $\begin{array}{l}\text { multi- } \\
\text { adjusted }^{c}\end{array}$ & $\begin{array}{l}\text { values > } \\
\text { LOD }(\mathrm{N})_{a}\end{array}$ & median (IQR) ${ }^{\mathrm{b}}$ & $\begin{array}{l}\text { multi- } \\
\text { adjusted }^{c}\end{array}$ \\
\hline \multicolumn{7}{|l|}{$\operatorname{Men}(N=2,863)$} \\
\hline \multicolumn{7}{|l|}{$\mathrm{BMI}_{\text {categories }}^{\S}$} \\
\hline Normal $(n=1,078)$ & $1,069(99.2)$ & $2.87(1.86-4.37)$ & $3.04 \pm 1.03$ & $1,078(100)$ & $0.8(0.4-1.6)$ & $0.93 \pm 1.03$ \\
\hline Overweight $(\mathrm{n}=1,306)$ & $1,298(99.4)$ & $3.10(1.90-4.63)$ & $3.12 \pm 1.02$ & $1,306(100)$ & $1.4(0.7-2.7)$ & $1.47 \pm 1.03$ \\
\hline Obese $(n=479)$ & 477 (99.6) & $3.46(2.13-5.48)$ & $3.37 \pm 1.04$ & $479(100)$ & $2.2(1.3-4.3)$ & $2.24 \pm 1.05$ \\
\hline Test & $0.97^{\mathrm{NS}}$ & $19.32^{* * *}$ & $2.45^{\mathrm{NS}}$ & NA & $343.3^{* * *}$ & $140.6^{* * *}$ \\
\hline \multicolumn{7}{|l|}{ High \%body fat ${ }^{\S \S}$} \\
\hline No $(n=2,157)$ & $2,144(99.4)$ & $2.94(1.87-4.46)$ & $3.10 \pm 1.02$ & $2,157(100)$ & $1.0(0.5-2.1)$ & $1.17 \pm 1.02$ \\
\hline Yes $(n=706)$ & $700(99.2)$ & $3.40(2.09-5.48)$ & $3.21 \pm 1.03$ & $700(100)$ & $2.0(1.1-4.3)$ & $1.98 \pm 1.04$ \\
\hline Test & $0.49^{\mathrm{NS}}$ & $15.48^{* * *}$ & $0.80^{\mathrm{NS}}$ & $\mathrm{NA}$ & $224.2^{* * *}$ & $126.2^{* * *}$ \\
\hline \multicolumn{7}{|l|}{ Abdominal obesity ${ }^{\S \S \S}$} \\
\hline No $(n=2,182)$ & 2166 (99.3) & $2.93(1.86-4.46)$ & $3.04 \pm 1.02$ & $2182(100)$ & $1.0(0.5-2.0)$ & $1.15 \pm 1.02$ \\
\hline Yes $(n=681)$ & $678(99.6)$ & $3.50(2.12-5.67)$ & $3.41 \pm 1.03$ & $681(100)$ & $2.2(1.2-4.3)$ & $2.12 \pm 1.04$ \\
\hline Test & 0.59 & $26.48^{* * * *}$ & $8.66^{* *}$ & NA & $261.3^{* * *}$ & $184.5^{* * *}$ \\
\hline \multicolumn{7}{|l|}{ Women $(\mathrm{N}=3,167)$} \\
\hline \multicolumn{7}{|l|}{$\mathrm{BMI}_{\text {categories }}^{\S}$} \\
\hline Normal $(\mathrm{n}=1,812)$ & 1,797 (99.2) & $2.59(1.64-4.08)$ & $2.78 \pm 1.02$ & $1,812(100)$ & $0.8(0.5-1.8)$ & $0.95 \pm 1.03$ \\
\hline Overweight $(n=902)$ & $897(99.5)$ & $2.90(1.77-4.62)$ & $2.96 \pm 1.03$ & $902(100)$ & $1.9(0.9-3.6)$ & $1.88 \pm 1.03$ \\
\hline Obese $(n=453)$ & $449(99.1)$ & $3.29(2.12-5.08)$ & $3.43 \pm 1.04$ & $453(100)$ & $3.8(1.9-7.0)$ & $3.53 \pm 1.05$ \\
\hline Test & $0.71^{\mathrm{NS}}$ & $39.49^{* * *}$ & $9.91^{* * *}$ & NA & $647.8^{* * *}$ & $337.5^{* * *}$ \\
\hline \multicolumn{7}{|l|}{ High \%body fat ${ }^{\S \S}$} \\
\hline No $(n=2,320)$ & $2,300(99.1)$ & $2.59(1.63-4.16)$ & $2.81 \pm 1.02$ & $2,320(100)$ & $1.0(0.5-2.2)$ & $1.13 \pm 1.02$ \\
\hline Yes $(n=847)$ & $843(99.5)$ & $3.20(2.11-4.92)$ & $3.22 \pm 1.03$ & $847(100)$ & $2.6(1.4-5.1)$ & $2.55 \pm 1.04$ \\
\hline Test & $1.25^{\mathrm{NS}}$ & $48.92^{* * *}$ & $12.12^{* * *}$ & NA & $396.1^{* * *}$ & $315.9^{* * *}$ \\
\hline \multicolumn{7}{|l|}{ Abdominal obesity $\S^{\S \S}$} \\
\hline No $(n=2,193)$ & 2,177 (99.3) & $2.57(1.66-4.14)$ & $2.79 \pm 1.02$ & $2,193(100)$ & $1.0(0.5-2.1)$ & $1.08 \pm 1.02$ \\
\hline Yes $(\mathrm{n}=974)$ & $966(99.2)$ & $3.20(2.04-5.01)$ & $3.22 \pm 1.03$ & $974(100)$ & $2.6(1.4-5.2)$ & $2.51 \pm 1.04$ \\
\hline Test & $0.08^{\mathrm{NS}}$ & $48.11^{* * *}$ & $16.27^{* * *}$ & $\mathrm{NA}$ & $462.6^{* * *}$ & $410.0^{* * *}$ \\
\hline \multicolumn{7}{|c|}{ 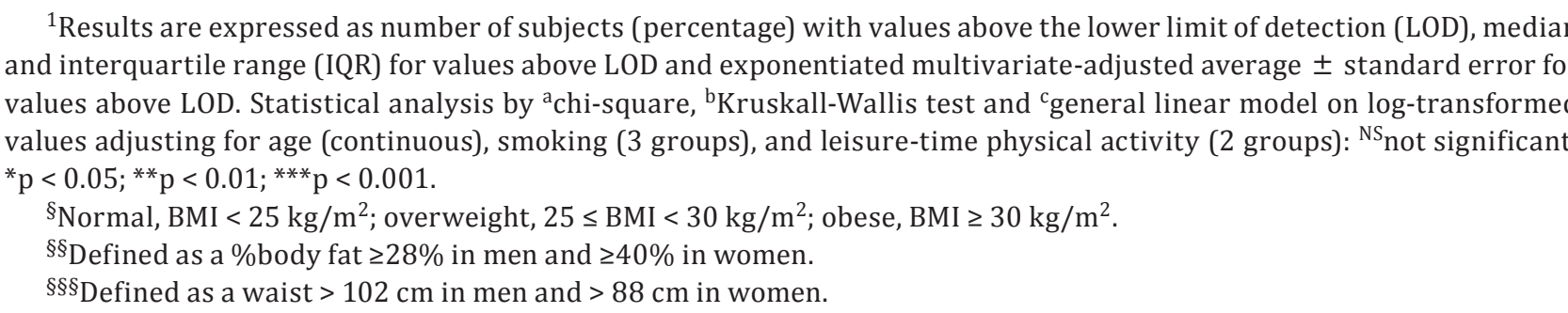 } \\
\hline
\end{tabular}

although we have no information on the former. Overall, our results suggest that increased IL-1 $\beta$ levels are associated with lower \%body fat levels, probably due to a reduced adipocyte differentiation.

It has been estimated that approximately $30 \%$ of circulating IL- 6 comes from adipose tissue [22]. In this study, obese subjects had higher IL-6 levels, a finding also reported by others [23]. Interestingly, after multivariate adjustment, abdominal obesity was significantly associated with IL-6 levels in both genders, a finding which is in agreement with recent literature [7,24]. Still, although all obesity markers were significantly and positively correlated with IL- 6 levels in both genders, these associations were no longer significant 
Table 4. Relationships between inflammatory and obesity markers, by gender ${ }^{1}$

\begin{tabular}{|c|c|c|c|c|}
\hline & IL-1 $\beta$ & IL-6 & TNF- $\alpha$ & hs-CRP \\
\hline $\operatorname{Men}(N)$ & 1,732 & 2,678 & 2,844 & 2,862 \\
\hline \multicolumn{5}{|l|}{ Spearman correlation } \\
\hline BMI & $-0.057^{\mathrm{NS}}$ & $0.053^{* *}$ & $0.095^{* * *}$ & $0.359 * * *$ \\
\hline$\%$ Body fat & $-0.079^{* *}$ & $0.072^{* * *}$ & $0.114^{* * *}$ & $0.365^{* * *}$ \\
\hline Waist circumference & $-0.063^{* *}$ & $0.074^{* * *}$ & $0.122^{* * *}$ & $0.381^{* * *}$ \\
\hline \multicolumn{5}{|c|}{ Linear regression $^{\mathrm{a}}$} \\
\hline BMI & $-0.011(0.009)^{\mathrm{NS}}$ & $0.015(0.006)^{*}$ & $0.012(0.004)^{* *}$ & $0.082(0.005)^{* * *}$ \\
\hline \%Body fat & $-0.015(0.007)^{*}$ & $0.005(0.005)^{\mathrm{NS}}$ & $0.007(0.003)^{*}$ & $0.055(0.004)^{* * *}$ \\
\hline Waist circumference & $-0.003(0.003)^{\mathrm{NS}}$ & $0.007(0.002)^{* *}$ & $0.006(0.001)^{* * *}$ & $0.031(0.002)^{* * *}$ \\
\hline \multicolumn{5}{|c|}{ Ridge regression ${ }^{\mathrm{b}}$} \\
\hline BMI & $-0.002(0.020)^{\mathrm{NS}}$ & $-0.001(0.014)^{\mathrm{NS}}$ & $-0.004(0.009)^{\mathrm{NS}}$ & $0.025(0.010)^{*}$ \\
\hline$\%$ Body fat & $-0.019(0.010)^{\mathrm{NS}}$ & $-0.007(0.007)^{\mathrm{NS}}$ & $-0.001(0.004)^{\mathrm{NS}}$ & $0.019(0.005)^{* * *}$ \\
\hline Waist & $0.004(0.007)^{\mathrm{NS}}$ & $0.009(0.005)^{\mathrm{NS}}$ & $0.008(0.003)^{*}$ & $0.016(0.004)^{* * * *}$ \\
\hline Women (N) & 2,025 & 2,906 & 3,143 & 3,167 \\
\hline \multicolumn{5}{|l|}{ Spearman correlation } \\
\hline BMI & $-0.048^{\mathrm{NS}}$ & $0.095^{* * *}$ & $0.122^{* * *}$ & $0.475^{* * *}$ \\
\hline$\%$ Body fat & $-0.082^{* * *}$ & $0.080^{* * *}$ & $0.122^{* * *}$ & $0.433^{* * *}$ \\
\hline Waist circumference & $-0.055^{\mathrm{NS}}$ & $0.109^{* * *}$ & $0.141^{* * *}$ & $0.462^{* * *}$ \\
\hline \multicolumn{5}{|c|}{ Linear regression $^{\mathrm{a}}$} \\
\hline BMI & $-0.005(0.007)^{*}$ & $0.026(0.005)^{* * *}$ & $0.019(0.003)^{* * *}$ & $0.106(0.004)^{* * *}$ \\
\hline$\%$ Body fat & $-0.010(0.004)^{\mathrm{NS}}$ & $0.010(0.003)^{* *}$ & $0.006(0.002)^{* *}$ & $0.058(0.003)^{* * *}$ \\
\hline Waist circumference & $-0.004(0.003)^{N S}$ & $0.011(0.002)^{* * *}$ & $0.007(0.001)^{* * *}$ & $0.040(0.002)^{* * *}$ \\
\hline \multicolumn{5}{|c|}{ Ridge regression $\mathrm{b}$} \\
\hline BMI & $0.029(0.015)^{\mathrm{NS}}$ & $0.020(0.012)^{\mathrm{NS}}$ & $0.021(0.007)^{* *}$ & $0.055(0.008)^{* * *}$ \\
\hline$\%$ Body fat & $-0.017(0.006)^{* *}$ & $-0.007(0.005)^{\mathrm{NS}}$ & $-0.007(0.003)^{*}$ & $0.017(0.004)^{* * *}$ \\
\hline Waist circumference & $-0.007(0.005)^{\mathrm{NS}}$ & $0.007(0.004)^{\mathrm{NS}}$ & $0.003(0.003)^{\mathrm{NS}}$ & $0.015(0.003)^{* * *}$ \\
\hline
\end{tabular}

${ }^{1}$ Only for participants with values above lower levels of detection. All analyses were performed on logtransformed variables, adjusting for age, smoking status and leisure-time physical activity. For linear and ridge regression, results are presented as slope (standard error): ${ }^{\mathrm{NS}}$ not significant; ${ }^{*} \mathrm{p}<0.05 ;{ }^{* *} \mathrm{p}<0.01$; *** $\mathrm{p}<0.001$.

${ }^{\mathrm{a}}$ For each obesity marker separately. ${ }^{\mathrm{b}} \mathrm{All}$ obesity markers taken together.

after multivariate ridge regression. Our results are partly in agreement with one study [25] which found no significant correlation between abdominal fat distributions measured by ultrasonography and circulating IL- 6 levels. Conversely, the lack of association between \%body fat and IL-6 levels is not in agreement with a previous study [7]. A possible explanation for this discrepancy is that the previous study included only obese subjects, thus limiting the generalization of the findings. Overall, our results suggest that abdominal obesity is associated with increased IL- 6 levels in both genders, but that this increase in IL- 6 levels is not mediated by any specific obesity marker (BMI, waist circumference, or \%body fat). Nevertheless, further studies are needed to better assess the specific effects of selected obesity markers on IL-6 levels.

TNF- $\alpha$ is mainly secreted by macrophages after stimulation by bacterial lipopolysaccharides and stimulates the production of other cytokines such as IL-6 [24]. Adipocytes have also been shown to produce TNF- $\alpha$ [26], and high TNF- $\alpha$ levels have been found in obese subjects [27]. In both genders, subjects with abdominal obesity had higher TNF- $\alpha$ levels, and these differences persisted after multivariate adjustment; conversely, increased BMI and \%body fat were associated with increased TNF- $\alpha$ levels in women only. Only BMI 
(in women) and waist circumference were independently and positively associated with TNF- $\alpha$ levels, a result which is partly in agreement with some smaller studies [23] but not with others [24, 25]. Again, no independent association between \%body fat and TNF- $\alpha$ levels was found, a finding in contradiction with a previous study [7]. In women, BMI, but not waist circumference, was associated with TNF- $\alpha$, a finding which is in agreement with another study [25]. Finally, obese subjects have a higher prevalence of diabetes, a condition which increases inflammatory markers. Still, further adjustment on diabetic status (defined as fasting plasma glucose $\geq 7 \mathrm{mmol} / \mathrm{l}$ and/or presence of antidiabetic treatment) did not change the results (supplementary tables 1 and 2). Overall, our results suggest that both BMI and waist circumference might be associated with an increased production of TNF- $\alpha$, while the effect of \%body fat awaits further investigation.

CRP is an acute-phase reactant mainly synthesized in the liver. Several studies have shown that hs-CRP is associated with most obesity markers [7]. Indeed, all obesity markers were significantly and positively associated with hs-CRP levels, but likely due to differing metabolic pathways. For instance, the high fat mass (overall or in the abdominal region) might lead to increased production of TNF- $\alpha$ and IL-6, which in turn increase hepatic production of hs-CRP [28], while the relationship with BMI could be simply due to increased arthritis or hyperuricemia [29].

The major strength of our study is that we used a large, population-based sample representative of the Swiss population, that a precise characterization of the participants was performed, and that we used a statistical method correcting for correlations amongst independent variables. However, we should also mention some limitations of our study. Although the participation rate was similar to other epidemiological studies [30], it was rather low (41\%), which might limit the generalization of findings. It has also been shown that African Americans have lower visceral adipose tissue but similar or higher concentrations of inflammatory biomarkers than Caucasians [31]; as only data from Caucasian subjects was analyzed, our findings may not apply to other ethnicities. Further, all measures of association (Spearman correlations, linear or ridge regression coefficients) were relatively low for all inflammatory markers, except for hs-CRP, suggesting that obesity markers exert only a modest impact on IL-1 $\beta$, IL-6, and TNF- $\alpha$ levels.

In summary, our results suggest that obesity markers are significantly, moderately and differentially associated with cy tokine levels. \%Body fat is negatively associated with IL-1 $\beta$ levels; abdominal obesity is associated with increased IL- 6 levels in both genders, but that this increase in IL-6 levels is not mediated by any specific obesity marker; both BMI and waist circumference are associated with an increased production of TNF- $\alpha$, while the effect of \%body fat awaits further investigation. Conversely, all obesity markers are strongly associated with hs-CRP levels.

\section{Acknowledgements}

The CoLaus study was supported by research grants from GlaxoSmithKline, the Faculty of Biology and Medicine of Lausanne, Switzerland and the Swiss National Science Foundation (grant no: 33CSCO122661). The authors also express their gratitude to the participants in the Lausanne CoLaus study and to the investigators who have contributed to the recruitment, in particular Yolande Barreau, Anne-Lise Bastian, Binasa Ramic, Martine Moranville, Martine Baumer, Marcy Sagette, Jeanne Ecoffey and Sylvie Mermoud for data collection. Murielle Bochud is supported by the Swiss School of Public Health Plus (SSPH+). 
Marques-Vidal et al.: Association between Inflammatory and Obesity Markers in a Swiss Population-Based Sample (CoLaus Study)

\section{Disclosure Statement}

Pedro Marques-Vidal and Gérard Waeber received an unrestricted grant for GSK to build the CoLaus study. The other authors report no conflict of interest.

\section{References}

1 Ridker PM, Hennekens CH, Buring JE, Rifai N: C-reactive protein and other markers of inflammation in the prediction of cardiovascular disease in women. N Engl J Med 2000;342:836-843.

2 Spranger J, Kroke A, Mohlig M, Hoffmann K, Bergmann MM, Ristow M, Boeing H, Pfeiffer AF: Inflammatory cytokines and the risk to develop type 2 diabetes: results of the prospective population-based European Prospective Investigation into Cancer and Nutrition (EPIC)-Potsdam study. Diabetes 2003;52:812-817.

3 Wozniak SE, Gee LL, Wachtel MS, Frezza EE: Adipose tissue: the new endocrine organ? A review article. Dig Dis Sci 2009;54:1847-1856.

- 4 Balistreri CR, Caruso C, Candore G: The role of adipose tissue and adipokines in obesity-related inflammatory diseases. Mediators Inflamm 2010;2010:802078.

- 5 Deurenberg P, Deurenberg YM, Wang J, Lin FP, Schmidt G: The impact of body build on the relationship between body mass index and percent body fat. Int J Obes Relat Metab Disord 1999;23:537-542.

- 6 Thorand B, Baumert J, Döring A, Herder C, Kolb H, Rathmann W, Giani G, Koenig W: Sex differences in the relation of body composition to markers of inflammation. Atherosclerosis 2006;184:216-224.

7 Park HS, Park JY, Yu R: Relationship of obesity and visceral adiposity with serum concentrations of CRP, TNF-alpha and IL-6. Diabetes Res Clin Pract 2005;69:29-35.

8 Miles J, Shevlin M: Applying Regression and Correlation. London, Sage Publications, 2001.

- 9 Marquardt DW, Snee RD: Ridge regression in practice. Am Statist 1975;29:3-20.

10 Firmann M, Mayor V, Marques Vidal P, Bochud M, Pécoud A, Hayoz D, Paccaud F, Preisig M, Song KS, Yuan X, Danoff TM, Stirnadel HA, Waterworth DM, Mooser V, Waeber G, Vollenweider P: The CoLaus study: a population-based study to investigate the epidemiology and genetic determinants of cardiovascular risk factors and metabolic syndrome. BMC Cardiovasc Disord 2008;8:6.

$\rightarrow 11$ Lean ME, Han TS, Morrison CE: Waist circumference as a measure for indicating need for weight management. BMJ 1995;311:158-161.

12 Ghosh S, Meister D, Cowen S, Hannan WJ, Ferguson A: Body composition at the bedside. Eur J Gastroenterol Hepatol 1997; 9:783-788.

13 Martin A, O’Sullivan AJ, Brown MA: Body composition and energy metabolism in normotensive and hypertensive pregnancy. BJOG 2001;108:1263-1271.

14 Steiner MC, Barton RL, Singh SJ, Morgan MD: Bedside methods versus dual energy X-ray absorptiometry for body composition measurement in COPD. Eur Respir J 2002;19:626-631.

-15 Simpson JA, Lobo DN, Anderson JA, Macdonald IA, Perkins AC, Neal KR, Allison SP, Rowlands BJ: Body water compartment measurements: a comparison of bioelectrical impedance analysis with tritium and sodium bromide dilution techniques. Clin Nutr 2001;20:339-343.

-16 Lee SA, Kallianpur A, Xiang YB, Wen W, Cai Q, Liu D, Fazio S, Linton MF, Zheng W, Shu XO: Intra-individual variation of plasma adipokine levels and utility of single measurement of these biomarkers in populationbased studies. Cancer Epidemiol Biomarkers Prev 2007;16:2464-2470.

17 von Känel R, Begré S, Abbas CC, Saner H, Gander ML, Schmid JP: Inflammatory biomarkers in patients with posttraumatic stress disorder caused by myocardial infarction and the role of depressive symptoms. Neuroimmunomodulation 2010;17:39-46.

18 Marques Vidal P, Bochud M, Bastardot F, Lüscher T, Ferrero F, Gaspoz JM, Paccaud F, Urwyler A, Von Känel R, Hock C, Waeber G, Preisig M, Vollenweider P: Levels and determinants of inflammatory biomarkers in a Swiss population-based sample (CoLaus study). PLoS One 2011;6:e21002.

19 Hoerl QE, Kennard RW: Ridge regression: biased estimation for nonorthogonal problems. Technometrics 1970;12:55-67.

20 Chida D, Osaka T, Hashimoto 0, Iwakura Y: Combined interleukin-6 and interleukin-1 deficiency causes obesity in young mice. Diabetes 2006;55:971-977.

-21 Brambilla F, Monti D, Franceschi C: Plasma concentrations of interleukin-1-beta, interleukin-6 and tumor necrosis factor-alpha, and of their soluble receptors and receptor antagonist in anorexia nervosa. Psychiatry Res 2001;103:107-114.

22 Mohamed-Ali V, Goodrick S, Rawesh A, Katz DR, Miles JM, Yudkin JS, Klein S, Coppack SW: Subcutaneous adipose tissue releases interleukin-6, but not tumor necrosis factor-alpha, in vivo. J Clin Endocrinol Metab 1997;82:4196-4200.

23 Bahceci M, Gokalp D, Bahceci S, Tuzcu A, Atmaca S, Arikan S: The correlation between adiposity and adiponectin, tumor necrosis factor alpha, interleukin- 6 and high sensitivity c-reactive protein levels. Is adipocyte size associated with inflammation in adults? J Endocrinol Invest 2007;30:210-214. 
24 Bruun JM, Verdich C, Toubro S, Astrup A, Richelsen B: Association between measures of insulin sensitivity and circulating levels of interleukin-8, interleukin- 6 and tumor necrosis factor-alpha. Effect of weight loss in obese men. Eur J Endocrinol 2003;148:535-542.

-25 Fenkci S, Rota S, Sabir N, Sermez Y, Guclu A, Akdag B: Relationship of serum interleukin-6 and tumor necrosis factor alpha levels with abdominal fat distribution evaluated by ultrasonography in overweight or obese postmenopausal women. J Investig Med 2006;54:455-460.

26 Coppack SW: Pro-inflammatory cytokines and adipose tissue. Proc Nutr Soc 2001;60:349-356.

27 Moon YS, Kim DH, Song DK: Serum tumor necrosis factor-alpha levels and components of the metabolic syndrome in obese adolescents. Metabolism 2004;53:863-867.

28 Khaodhiar L, Ling PR, Blackburn GL, Bistrian BR: Serum levels of interleukin-6 and C-reactive protein correlate with body mass index across the broad range of obesity. J Parenter Enteral Nutr 2004;28:410415.

29 Magliano M: Obesity and arthritis. Menopause Int 2008;14:149-154.

30 Tolonen H, Koponen P, Aromaa A, Conti S, Graff-Iversen S, Grøtvedt L, Kanieff M, Mindel J, Natunen S, Primatesta P, Verschuren M, Viet L, Kuulasmaa K, for the Feasibility of a Eu ropean Health Examination Survey P: Review of Health Examination Surveys in Europe. Helsinki, National Public Health Institute (KTL), 2008, B18/2008, pp 1-379.

-31 Carroll JF, Fulda KG, Chiapa AL, Rodriquez M, Phelps DR, Cardarelli KM, Vishwanatha JK, Cardarelli R: Impact of race/ethnicity on the relationship between visceral fat and inflammatory biomarkers. Obesity (Silver Spring) 2009;17:1420-1427. 